\title{
Analysis of Posterior Chain Muscle Symmetry in Junior Badminton Players of South Asia
}

\author{
${ }^{1}$ Abhinav Bindra Targeting Performance, Mohali, India \\ ${ }^{2}$ Abhinav Bindra Targeting Performance, Bangalore, India \\ ${ }^{3}$ Fortis Hospital, Mohali, India \\ Submission: November 28, 2018; Published: December 06, 2018 \\ *Corresponding author: Manan Vora, Fortis Hospital, Mohali, India
}

Digpal Ranawat ${ }^{1,2}$, Manan Vora ${ }^{1,3 *}$, Manit Arora ${ }^{1,3}$ and Apoorva Tiwari ${ }^{2}$

\begin{abstract}
Badminton is a physically demanding sport and it is not uncommon for players to have muscle imbalances. Detection and prevention of posterior muscle chain imbalances may help prevent injuries and result in overall improvement in performance. Accordingly, the study was proposed to analyse the posterior muscle chain symmetry in junior badminton players and understand the importance of prevention of muscle imbalance. A total of 100 players from South Asia between the ages of 8 and 15 years were analysed. Postural bench MF system of Tec nobody Italy was used. Variables measured were gender, height, age, body mass index, and experience in years, level at which they play, current pain, and clicks \& catches in the past 1 year. Our study showed that there is a significant difference in the lumbar load between the right and left side in amateur and professional badminton players and in the pelvic load between the right and left side in players with an experience of less and more than 5 years. Rest of the variables did not prove to be significant with respect to difference in scapular, lumbar and pelvic load. There needs to be a greater focus on prevention of muscle imbalances with the help of specific training, strength \& conditioning, and rehabilitation as part of the development of junior badminton players.
\end{abstract}

Keywords: Performance; Racquet sport; Muscle imbalance; Posture; Biomechanics

\section{Introduction}

The intermittent nature of badminton makes it hard to determine exactly what is happening physiologically, because so much is dependent on standard of players, the type of game being played, the duration of the play, coordination, mental acuity and the environmental conditions encountered Mikkelsen [1]. Great athletes make difficult moves look effortless with a combination of skill, strength, and balance and accordingly, train for smooth and fluid movement to help prevent muscle imbalances, mobility restrictions, stability problems, and injuries Cook [2]. It has been previously established that the biomechanical rationale for achieving and maintaining optimal posture is to move efficiently, free of impairment and dysfunction Kritz \& Cronin [3]. Muscle imbalance occurs when muscles become constantly shortened or lengthened in relation to each other Norris [4]. Various imbalance classifications have been suggested relating to muscles' structure, function and response to injury. Muscles have been classified as both postural and phasic types, and stability and movement synergists Norris [4]. It states that shortened muscle in a group shows a lowered irritability threshold and is recruited first in a movement, causing changes in motor programming. Few studies have taken place on muscle imbalance in sport. The relationship between hip muscle imbalance and occurrence of low back pain in athletes has been studied Nadler et al [5]. Shoulder muscle imbalance and subacromial impingement syndrome in overhead athletes has been documented Page [6]. Muscle imbalances of the lower extremities in competitive sports like basketball and volleyball have been analysed Sommer [7]. Additionally, strength imbalances in professional soccer players has been discussed as well Croisier, Ganteaume, Binet, Genty, \& Ferret [8].

Posterior chain muscle imbalance could either be a cause of or lead to potential postural problems. One recent study focused on the posture of badminton players. It analysed the reliability of postural measures in elite badminton players using Posture Pro 8 software which is used for photogrammetry assessment of posture Hébert-Losier \& Rahman [9]. The authors assessed the standing posture from anterior, lateral, and posterior photographs and extracted postural measures using visual landmarks as guide. Another study in the past did posture assessments from four photographs: anterior, posterior, lateral and oblique views Watson \& Mac Donncha [10]. There have been various other studies which have used certain methods to assess muscle imbalances and function. One such study used clinical movement analysis to identify muscle imbalances Padua \& Hirth [11]. Surface electromyography, a non-invasive technique for assessing muscle function and providing a basic understanding of the function of trunk muscles in both normal subjects and low back pain patients during specific postures and movements was done Oddsson \& De Luca [12] while another preliminary alternative approach in an 
attempt to assess muscle function in relation to both-performance \& injury prevention and muscular recovery after injury has been documented as well Schlumberger et al. [13]

A study on the epidemiology of injuries in elite badminton athletes showed that the most common region of pain in the body is the back Yung, Chan, Wong, Cheuk, \& Fong [14]. Goh, Mokhtar, \& R. Mohamad Ali, [15] Studies have shown that most sports injuries are related to flexibility, posture, acceleration, clinical defects, and previous injury Watson [16]. A study was also conducted on the sports injuries in footballers related to defects of posture and body mechanics with the objective being to investigate possible relationships between the incidence of sports injury and the existence of body mechanics defect in players Watson [17]. Studies co-relating injuries to muscular imbalances have been documented such as a relationship between shoulder mobility, rotator muscles' strength and scapular symmetry, and shoulder injuries and/or pain in elite volleyball athletes Wang \& Cochrane [18] A prospective study of overuse knee injuries among female athletes with muscle imbalances and structural abnormalities has been conducted Devan, Pescatello, Faghri, \& Anderson [19]. The purpose of this study was to identify the modifiable and non-modifiable factors that contribute to posterior chain muscle imbalances in badminton players, resulting in potential postural problems, back pain and increased risk of injury. Non-modifiable factors include gender, height, age and years of experience. Modifiable factors include body mass index, level, current pains, clicks and catches in the body.

\section{Methodology}

One hundred junior badminton players under the aegis of Badminton Association of India (BAI) were recruited for the study. Informed consent from the players, legal guardians and coaches was taken prior to participation. Approval from the BAI was taken prior to initiation of the study. All players were screened using a combination of a questionnaire and machine analysis.
The questionnaire consisted of a self-developed item set with focus on demographics, injury history, treatment history, playing career history and current injury state. The demographic data included age, sex, height, weight, and dominant hand. The injury history included questions regarding injuries in the past, their severity, whether they occurred during competition, training or daily activity, whether it prevented the player from taking part in a competition and/or training and/or daily activity, and if the pain was more during a particular badminton stroke. The treatment history questioned the form of treatment taken for the injuries, whether it was oral medication, physiotherapy, surgery, or any other.

Playing career history included information regarding the age at which the player began playing badminton, whether the player has a dedicated coach and/or trainer, age at which he/she began playing badminton tournaments, and current professional level. Current injury state involved questions regarding any current pain faced by the player, and whether the player has experienced any clicks, cracks or catches in the body in the last 12 months. The machine analysis was done by conducting a biomechanical assessment of posture. Postural bench MF system of Tecnobody Italy (Figure 1) was used to assess the posture. The Postural Bench system is equipped with two tilting flat surfaces (head and trunk surface A and lower limbs surface B) which pivot on the dock. The athlete is made to lie down flat on the bench. As you tilt the system from either end (Figure 2), contraction of the back muscle structure takes place, emphasizing the rotations and muscular dissymmetry. The assessment module of the Postural Bench system allows one to monitor, in real time, the symmetry of the posterior chain in three fundamental points: scapular, lumbar, and pelvic areas. At the end of the 2 minute test, the report (Figure 3 ) presents a clear picture about the muscular symmetry between right and left sides, in which it shows in percentage terms the load developed from the posterior chain.

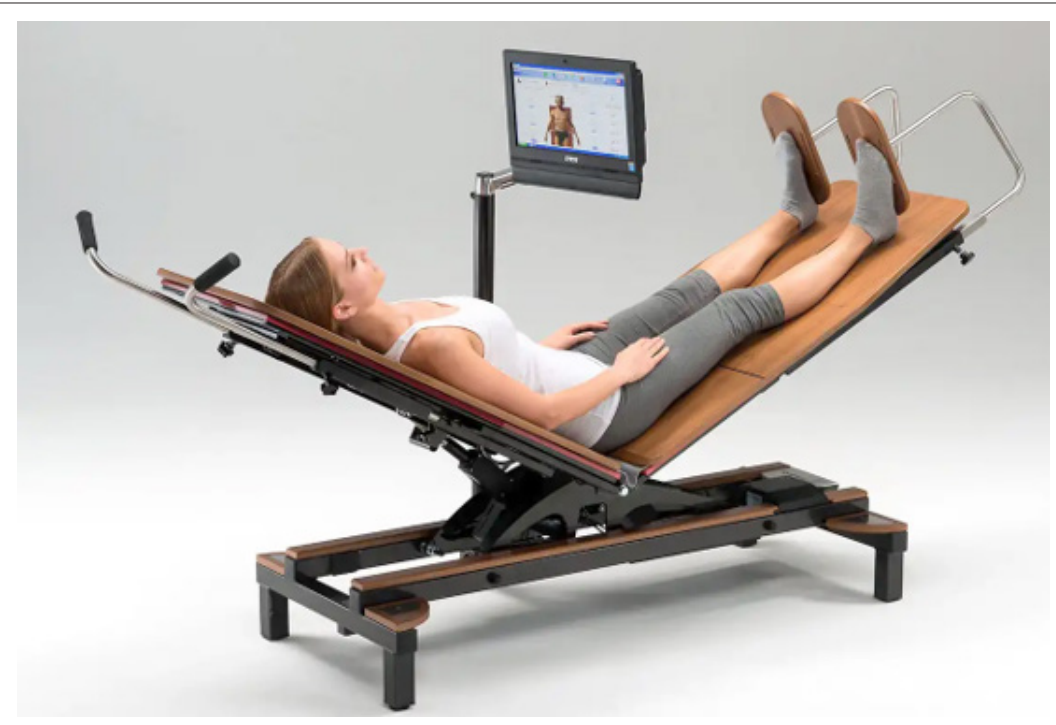

Figure 1: Postural Bench MF System of Tecnobody Italy. 


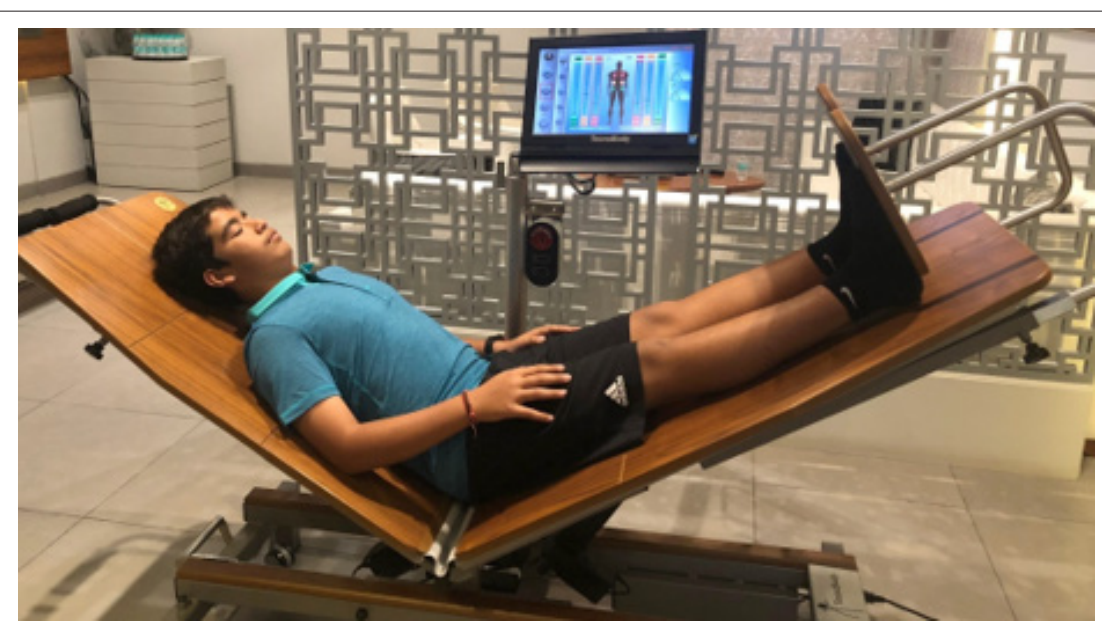

Figure 2: BAI player getting assessed on the Postural Bench MF System.

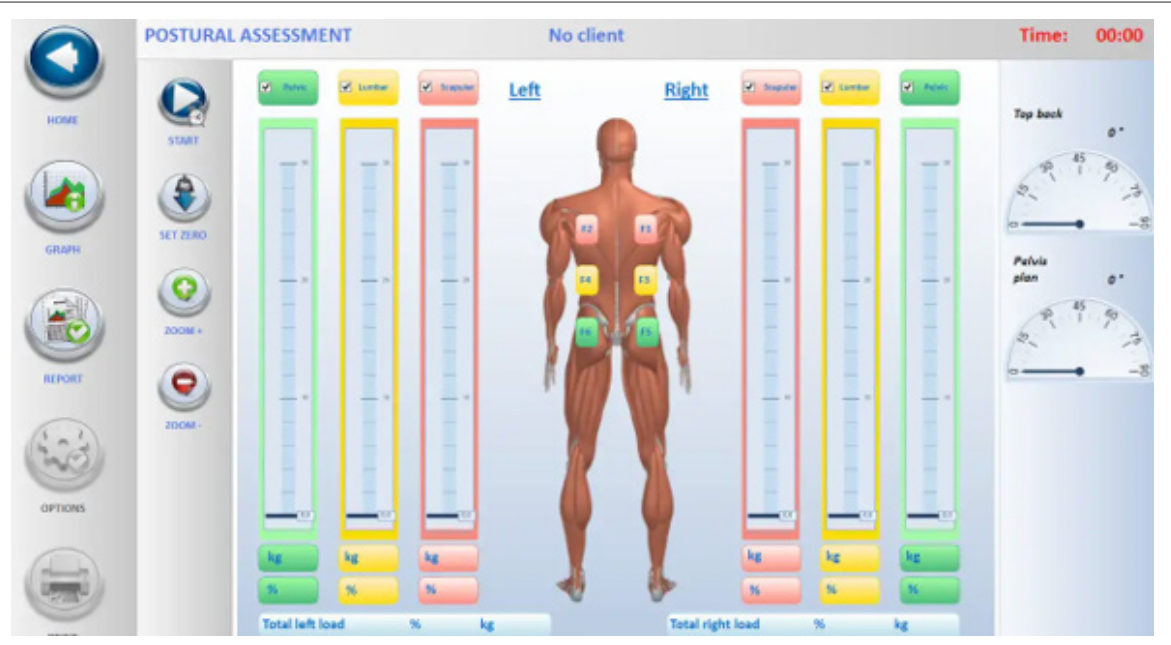

Figure 3: Postural Bench MF System screen.

Table 1: Difference in Scapular load between right and left sides in \%.

\begin{tabular}{|c|c|c|c|c|}
\hline Variables & Groups & $\mathbf{N}$ & Mean \pm Sd & 'P' \\
\hline \multirow{2}{*}{ Gender } & Male & 59 & $6.25 \pm 6.44$ & \multirow{2}{*}{1} \\
\hline & Female & 41 & $6.46 \pm 10.79$ & \\
\hline \multirow{2}{*}{ Height (in cms) } & Below 150 & 21 & $5.70 \pm 7.01$ & \multirow{2}{*}{0} \\
\hline & Above150 & 79 & $6.51 \pm 8.88$ & \\
\hline \multirow{2}{*}{ Age (in years) } & $<12$ & 39 & $5.58 \pm 4.76$ & \multirow{2}{*}{0} \\
\hline & $>12$ & 61 & $6.82 \pm 10.14$ & \\
\hline \multirow{2}{*}{ Bmi $\left(\operatorname{In~} \mathrm{Kg} / \mathrm{m}^{2}\right)$} & $<18$ & 42 & $6.81 \pm 9.80$ & \multirow{2}{*}{0} \\
\hline & $>18$ & 58 & $6.00 \pm 7.38$ & \\
\hline \multirow{2}{*}{ Experience (In Years) } & $<5$ & 44 & $6.74 \pm 9.67$ & \multirow{2}{*}{0} \\
\hline & $>5$ & 56 & $6.02 \pm 7.41$ & \\
\hline \multirow{2}{*}{ Level } & Amateur & 34 & $5.41 \pm 5.21$ & \multirow{2}{*}{0} \\
\hline & Professional & 66 & $6.81 \pm 9.70$ & \\
\hline \multirow{2}{*}{ Current Pain } & Yes & 24 & $7.71 \pm 11.3$ & \\
\hline & No & 76 & $5.90 \pm 7.33$ & 0 \\
\hline \multirow{2}{*}{ Clicks \& Catches in Past 1yr } & Yes & 23 & $5.54 \pm 4.14$ & \multirow{2}{*}{0} \\
\hline & No & 77 & $6.58 \pm 9.36$ & \\
\hline
\end{tabular}

*Significant difference level at (0.05).
Table 2: Difference in Lumbar load between right and left sides in \%.

\begin{tabular}{|c|c|c|c|c|}
\hline Variables & Groups & $\mathbf{N}$ & Mean \pm Sd & 'P' \\
\hline \multirow{2}{*}{ Gender } & Male & 59 & $7.59 \pm 7.04$ & \multirow{2}{*}{0.16} \\
\cline { 2 - 4 } & Female & 41 & $6.37 \pm 5.92$ & \\
\hline \multirow{2}{*}{ Height (In Cms) } & Below 150 & 21 & $7.39 \pm 7.32$ & \multirow{2}{*}{0.8} \\
\cline { 2 - 4 } & Above150 & 79 & $6.96 \pm 6.47$ & \\
\hline \multirow{2}{*}{ Age (In Years) } & $<12$ & 39 & $7.07 \pm 5.59$ & \multirow{2}{*}{0.12} \\
\cline { 2 - 4 } & $>12$ & 61 & $7.10 \pm 7.22$ & \\
\hline \multirow{2}{*}{ Bmi (In Kg/M $\left.{ }^{2}\right)$} & $<18$ & 42 & $6.85 \pm 6.78$ & \multirow{2}{*}{0.66} \\
\cline { 2 - 4 } & $>18$ & 58 & $7.27 \pm 6.52$ & \\
\hline \multirow{2}{*}{ Experience (In Years) } & $<5$ & 44 & $6.13 \pm 6.15$ & \multirow{2}{*}{0.47} \\
\cline { 2 - 4 } & $>5$ & 56 & $7.85 \pm 6.89$ & \\
\hline \multirow{2}{*}{ Level } & Amateur & 34 & $6.01 \pm 4.90$ & \multirow{2}{*}{$0.05 *$} \\
\cline { 2 - 4 } & Professional & 66 & $7.65 \pm 7.29$ & \\
\hline \multirow{2}{*}{ Current Pain } & Yes & 24 & $7.39 \pm 5.32$ & \multirow{2}{*}{0.25} \\
\cline { 2 - 4 } & No & 76 & $7.00 \pm 6.98$ & \\
\hline \multirow{2}{*}{ Clicks \& Catches in Past 1Yr } & Yes & 23 & $6.89 \pm 4.83$ & \multirow{2}{*}{0.08} \\
\cline { 2 - 4 } & No & 77 & $7.15 \pm 7.07$ & \\
\hline
\end{tabular}

*Significant difference level at (0.05). 
Table 3: Difference in Pelvic load between right and left sides in \%.

\begin{tabular}{|c|c|c|c|c|}
\hline Variables & Groups & $\mathbf{N}$ & Mean \pm Sd & 'P' \\
\hline \multirow{2}{*}{ Gender } & Male & 59 & $10.54 \pm 14.85$ & \multirow{2}{*}{0.09} \\
\hline & Female & 41 & $11.73 \pm 18.93$ & \\
\hline \multirow{2}{*}{ Height (In Cms) } & Below 150 & 21 & $11.21 \pm 20.28$ & \multirow{2}{*}{0.94} \\
\hline & Above150 & 79 & $11.53 \pm 14.33$ & \\
\hline \multirow{2}{*}{ Age (In Years) } & $<12$ & 39 & $10.20 \pm 11.98$ & \multirow{2}{*}{0.39} \\
\hline & $>12$ & 61 & $12.07 \pm 21.07$ & \\
\hline \multirow{2}{*}{ Bmi (In Kg/M $\left.{ }^{2}\right)$} & $<18$ & 42 & $12.28 \pm 24.34$ & \multirow{2}{*}{0.23} \\
\hline & $>18$ & 58 & $10.66 \pm 11.64$ & \\
\hline \multirow{2}{*}{ Experience (In Years) } & $<5$ & 44 & $8.81 \pm 7.45$ & \multirow{2}{*}{$0.02^{*}$} \\
\hline & $>5$ & 56 & $13.33 \pm 23.04$ & \\
\hline \multirow{2}{*}{ Level } & Amateur & 34 & $9.20 \pm 8.14$ & \multirow{2}{*}{0.15} \\
\hline & Professional & 66 & $12.44 \pm 21.36$ & \\
\hline \multirow{2}{*}{ Current Pain } & Yes & 24 & $7.31 \pm 6.40$ & \multirow[t]{2}{*}{0.07} \\
\hline & No & 76 & $12.61 \pm 20 \pm 21$ & \\
\hline \multirow{2}{*}{$\begin{array}{c}\text { Clicks \& Catches in Past } \\
1 \mathrm{yr}\end{array}$} & Yes & 23 & $7.50 \pm 6.48$ & \multirow[b]{2}{*}{0.08} \\
\hline & No & 77 & $12.49 \pm 20.10$ & \\
\hline
\end{tabular}

*Significant difference level at (0.05).

We recorded the difference in scapular, lumbar, and pelvic load (\%) from each athlete's report. The test was done using the Tecnobody machine in Abhinav Bindra Targeting Performance at Padukone-Dravid Centre for Sports Excellence in Bangalore. The data was categorized into variables (Tables 1-3) and the resulting categorical data was analysed by computing the Mean, Standard Deviation and T-test to identify the level significance in kinematic variables using Microsoft Excel and SPSS (16.0) software.

\section{Results}

A total of 100 junior South Asian Badminton players underwent the assessment. Out of the 100 players, 59 were male players and 41 were female players. 90 of them were from India, 4 each from Nepal and Sri Lanka, while 2 players were from Maldives. The age group was between 8 and 15 years. The data is presented in Tables 1-3.

Table 1 shows difference in scapular load (\%) between right and left sides of a body among various groups. Gender, height, age, BMI, experience in years, level at which they play, current pain, and clicks \& catches in the past 1 year were the variables. However, none of the variables showed a significant difference between the groups. As seen in Table 1, there is no significant difference in Scapular load with the variables.

Table 2 highlights the difference in lumbar load (\%) between right and left sides among groups. We observed a significant difference in terms of level at which they play (Graph 1). 34 players were amateur and 66 were professional players. Mean lumbar load difference in amateur players was $6.01 \pm 4.90 \%$ and in professional players was $7.65 \pm 7.29 \%$. The significant difference was 0.05 . There was no significant difference in terms of the other groups. As seen in Table 2, there is a significant difference in the level at which the players are playing.

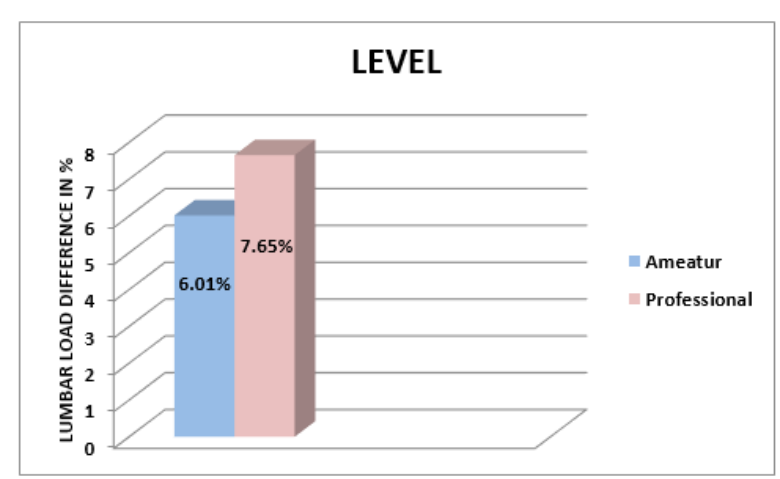

Graph 1: Significant difference in the level at which the players are playing- 0.05 .

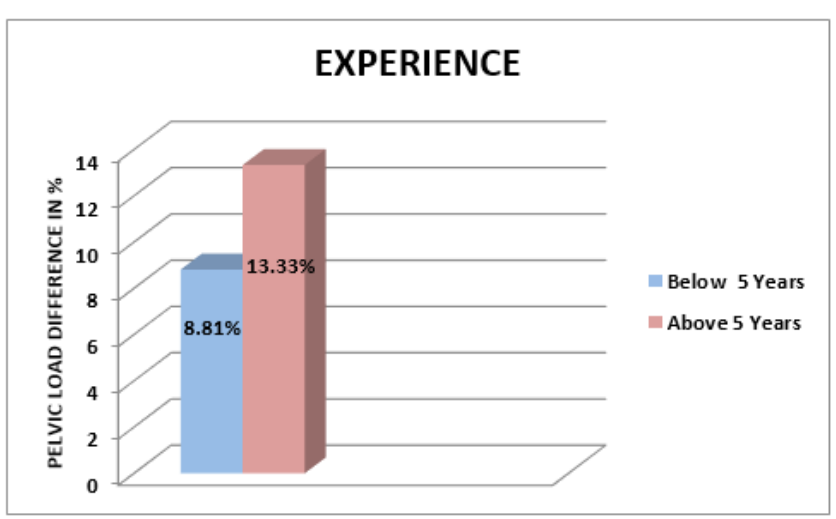

Graph 2: Significant difference with respect to years of experience- 0.02 
Table 3 highlights the difference in in pelvic load (\%) between right and left sides among groups. We observed a significant difference in terms of experience in years (Graph 2). 44 players had playing experience of less than 5 years and a mean of $8.81 \pm$ 7.45. 56 players had more than 5 years of playing experience and a mean of $13.33 \pm 23.04$. The significant difference was 0.02 . There was no significant difference in terms of the other groups. As seen in Table 3, there is significant difference with respect to years of experience

\section{Discussion}

Badminton requires specific physical conditioning in terms of action controls such as reaction time, foot stepping, and static or dynamic balances, which are essential motor demands in the sport Laffaye, Phomsoupha \& Dor [20]. In addition to moving back and forth on the court, players conduct various movement patterns during the game including twists, jumps, and swings to strike the shuttle-cock Phomsoupha \& Laffaye [21]. Due to the high physical demands of the game, it is not surprising that badminton players may have posterior muscle chain asymmetry.

The results of our study have highlighted certain factors that contribute to causing posterior muscle chain asymmetry, but it also sheds light upon the lack of importance given by players and coaches in including a training and conditioning program in an athlete's regimen that focuses on improving the muscle imbalance and posture of an athlete. Based on our results, we found that there is a significant difference in the lumbar load between the right and left side in amateur and professional badminton players. We also found a significant difference in the pelvic load between the right and left side in players with an experience of less and more than 5 years. Rest of the variables proved to be non-significant with respect to difference in scapular, lumbar and pelvic load. Non-modifiable factors include gender, height, age and years of experience. Modifiable factors include body mass index, level, current pains, clicks and catches in the body.

\section{Non-Modifiable Factors}

The factors in question here were gender, height, age and years of experience There was a significant difference in the pelvic load between the right and left side in players with an experience of less and more than 5 years. The result showed that the players with more experience had more difference in pelvic load compared to the ones with less experience. This proves that as players become more experienced after a number of years in this gruelling sport, they are more prone to hip muscle imbalance. The muscles around the pelvis may be imbalanced and lead to reduced levels of stability, mobility, flexibility and strength, eventually affecting a player's performance. The importance of pelvic stability has been well highlighted and the need for pelvic stability training to be incorporated in a badminton player's regimen is necessary Manan, Digpal, Apoorva, \& Manit [23]. This also shows that despite players having more than 5 years' experience in the sport, they may not have access to strength and conditioning specialists or specialised physiotherapists who can help train them in improving their muscle imbalance and that it is not being given the importance it needs. There was no significant difference observed between any of the other groups in terms of difference in scapular, lumbar, and pelvic load between the right and left side of the body.

\section{Modifiable Factors}

The factors being considered here were body mass index, level, current pains, clicks and catches in the body. There was a significant difference in the lumbar load between the right and left side in amateur and professional badminton players. The result showed that professional badminton players had more difference in lumbar load compared to the amateur players. A study conducted on football players showed that knee injuries were found to be associated with lumbar lordosis and sway back. Subjects who suffered from muscle strains had a higher incidence of lumbar lordosis, sway back and abnormal knee inter-space. It also stated that back injuries were associated with poor shoulder symmetry, scapulae abduction, back asymmetry, kyphosis, lordosis and scoliosis. In general, it was found that the incidence of ankle, back, knee and muscle injuries was influenced by the presence of defects of body mechanics and the results suggest that intervention to improve body mechanics would be likely to reduce the incidence of sports injuries in football Watson [10]

The importance of good posture and prevention of lumbar muscle imbalance needs to be highlighted to players and their coaches to help prevent injuries and maximise performance. There was no significant difference observed between any of the other groups in terms of difference in scapular, lumbar, and pelvic load between the right and left side of the body. There are various studies that have suggested methods to assess muscle function and help prevent muscle imbalance. It has been previously stated that muscle impairments contribute to postural abnormalities and are associated with movement impairments. The authors suggested that the additional information provided by a static standing posture assessment may assist the strength and conditioning professional in developing a strength programme that is more specific to the athlete's needs in order to enhance performance and possibly reduce the incidence of injury. To optimise function, an athlete should be suggested an integrated functional exercise program for stretching of potentially overactive and tight muscles, and for strengthening of underactive and weak musculature Padua \& Hirth [11].

The advantages of balance and stability training too have been highlighted. The authors indicate balance and stability training to be effective for gain in muscular strength and equalisation of muscular imbalances Heitkamp, Horstmann, Mayer, Weller, \& Dickhuth [22] Manan et al [23]. A few studies have also discussed the co-relation between muscular imbalance and low back pain and posture related problems. It has been observed that improved objective techniques for early diagnosis, treatment, and rehabilitation of patients with low back pain may help reduce costs and prevent the development of a chronic disability. The authors stated that the development of such techniques requires a detailed 
understanding of mechanisms controlling muscle activation in the presence of low back pain as well as objective ways of measuring and quantifying muscular function in the presence of low back pain. Another study showed the concept of hip muscle imbalance being associated with low back pain occurrence in female athletes. Their research further supported the need for the assessment and treatment of hip muscle imbalance in individuals with low back pain. In a previous study, we assessed hip stability, helping us pinpoint the exact region of muscle imbalance and treat it accordingly Manan et al [23].

Importance should also be given to injury prevention. Stretching before playing and cool down exercises after playing are necessary. It is also suggested that injury prevention programmes should concentrate on improving posture and the rehabilitation from previous injury, rather than flexibility. There were some limitations we faced in our study. Firstly, the participants included players between the ages of 8 and 15 years only. Secondly, the study could have included a wider geographical area including players from more Asian countries. Thirdly, an assessment after correction of muscle imbalance could have been done. This study opens up new grounds for further research. Further studies can address other variables not included in the present study. Additionally, targeted interventions are needed to prevent posterior muscle chain imbalance in athletes and the effect of such improvements on performance need to be determined.

\section{Conclusion}

This study shows that there is a significant difference in the lumbar load between the right and left side in amateur and professional badminton players and a significant difference in the pelvic load between the right and left side in players with an experience of less and more than 5 years. Professional players had more difference in lumbar load compared to amateur players and players with more than 5 years' experience had more difference in pelvic load compared to less experienced players. However, no significant difference in scapular, lumbar and pelvic load was seen across other variables. Understanding the need of injury prevention programmes, strength \& conditioning, and sports rehabilitation and its importance in overall improvement in badminton performance is vital and may help take a badminton player's fitness and game performance to a whole new level.

\section{References}

1. Mikkelsen F (1979) Physical Demands and Muscle Adaptation in Elite Badminton Players 1.

2. Cook G (2003) Athletic Body in Balance.

3. Kritz MF, Cronin J (2008) Static Posture Assessment Screen of Athletes: Benefits and Considerations. Strength \& Conditioning Journal 30(5):18-27.

4. Norris CM (1995) Spinal Stabilisation: 4. Muscle Imbalance and the Low Back. Physiotherapy 81(3): 127-138.

5. Nadler SF, Malanga GA, Feinberg JH, Prybicien M, Stitik TP, et al. (2001) Relationship Between Hip Muscle Imbalance and Occurrence of Low Back Pain in Collegiate Athletes: A Prospective Study. American Journal of Physical Medicine \& Rehabilitation 80(8): 572-577.
6. Page P (2011) Shoulder Muscle Imbalance and Subacromial Impingement Syndrome in Overhead Athletes. International Journal of Sports Physical Therapy 6(1): 51-58.

7. Sommer HM (1988) Patellar Chondropathy and Apicitis, and Muscle Imbalances of the Lower Extremities in Competitive Sports. Sports Medicine 5(6): 386-394.

8. Croisier JL, Ganteaume S, Binet J, Genty M, Ferret JM, et al. (2008) Strength Imbalances and Prevention of Hamstring Injury in Professional Soccer Players: A Prospective Study. The American Journal of Sports Medicine 36(8): 1469-1475.

9. Hébert Losier K, Rahman FA (2018) Reliability of postural measures in elite badminton players using Posture Pro 8 Physiotherapy Theory and Practice 34(6): 483-494.

10. Watson AW, Mac Donncha C (2000) A reliable technique for the assessment of posture: assessment criteria for aspects of posture. The Journal of Sports Medicine and Physical Fitness 40(3): 260-270.

11. Padua DA, Hirth CJ (2007) Clinical Movement Analysis to Identify Muscle Imbalances and Guide Exercise. Athletic Therapy Today 12(4): 10-14.

12. Oddsson LIE, De Luca, CJ (2003) Activation imbalances in lumbar spine muscles in the presence of chronic low back pain. Journal of Applied Physiology 94(4): 1410-1420.

13. Schlumberger A, Laube W, Bruhn S, Herbeck B, Dahlinger M, et al. (2006) Muscle imbalances - fact or fiction? Isokinetics and Exercise Science 14(1): 3-11.

14. Yung PSH, Chan RHK, Wong FCY, Cheuk PWL, Fong DTP, et al. (2007) Epidemiology of Injuries in Hong Kong Elite Badminton Athletes. Research in Sports Medicine 15(2): 133-146.

15. Goh SL, Mokhtar AR, Mohamad Ali M (2013) Badminton injuries in youth competitive players 53(1): 65-70.

16. Watson AW (2001) Sports injuries related to flexibility, posture, acceleration, clinical defects, and previous injury, in high-level players of body contact sports. International Journal of Sports Medicine 22(3): 222-225.

17. Watson AW (1995) Sports injuries in footballers related to defects of posture and body mechanics. The Journal of Sports Medicine and Physical Fitness 35(4): 289-294.

18. Wang H, Cochrane T (2001) Mobility impairment, muscle imbalance, muscle weakness, scapular asymmetry, and shoulder injury in elite volleyball athletes 41: 403-410.

19. Devan MR, Pescatello LS, Faghri P, Anderson J (2004) A Prospective Study of Overuse Knee Injuries Among Female Athletes with Muscle Imbalances and Structural Abnormalities. Journal of Athletic Training 39(3): 263-267.

20. Laffaye G, Phomsoupha M, Dor F (2015) Changes in the Game Characteristics of a Badminton Match: A Longitudinal Study through the Olympic Game Finals Analysis in Men's Singles. Journal of Sports Science \& Medicine 14(3): 584-590.

21. Phomsoupha M, Laffaye G (2015) The science of badminton: game characteristics, anthropometry, physiology, visual fitness and biomechanics. Sports Medicine (Auckland, New Zeeland.) 45(4): 473495.

22. Heitkamp HC, Horstmann T, Mayer F, Weller J, Dickhuth HH, et al. (2001) Gain in Strength and Muscular Balance After Balance Training International Journal of Sports Medicine 22(4): 285-290.

23. Manan V, Digpal R, Apoorva T, Manit A (2018) Analysis of static, dynamic and pelvic stability in junior badminton players of South Asia Journal of Sports Medicine and Therapy 3(4): 080-088. 
(C) (i) This work is licensed under Creative Commons Attribution 4.0 License

DOI: 10.19080/JPFMTS.2018.06.555676

\section{Your next submission with Juniper Publishers} will reach you the below assets

- Quality Editorial service

- Swift Peer Review

- Reprints availability

- E-prints Service

- Manuscript Podcast for convenient understanding

- Global attainment for your research

- Manuscript accessibility in different formats ( Pdf, E-pub, Full Text, Audio)

- Unceasing customer service

Track the below URL for one-step submission https://juniperpublishers.com/online-submission.php 